\title{
Resource Leveling Based on Backward Controlling Activity in Line of Balance
}

\author{
Lihui Zhang, Yaping Tang, and Jianxun Qi \\ School of Economics and Management, North China Electric Power University, Beijing 102206, China \\ Correspondence should be addressed to Yaping Tang; 1105205461@qq.com
}

Received 28 October 2016; Accepted 18 January 2017; Published 21 February 2017

Academic Editor: Alessandro Tasora

Copyright (C) 2017 Lihui Zhang et al. This is an open access article distributed under the Creative Commons Attribution License, which permits unrestricted use, distribution, and reproduction in any medium, provided the original work is properly cited.

The line of balance method that provides continuous and uninterrupted use of resources is one of the best methods for repetitive project resource management. This paper develops a resource leveling algorithm based on the backward controlling activity in line of balance. The backward controlling activity is a kind of special activity, and if its duration is prolonged the project duration could be reduced. It brings two advantages to the resource leveling: both the resource allocated on the backward activity and the project duration are reduced. A resource leveling algorithm is presented which permits the number of crews of the backward controlling activity to be reduced until the terminal situation is reached, where the backward controlling activity does not exist or the number of crews cannot be reduced. That adjustment enables the productivity of all activities to be consistent. An illustrative pipeline project demonstrates the improvement in resource leveling. And this study designed a MATLAB program to execute the design algorithm. The proposed model could help practitioners to achieve the goals of both resource leveling and project duration reduction without increasing any resource.

\section{Introduction}

Repetitive projects consist of group of activities that involve repetitive "units" of construction elements in construction projects such as highways, high-rise buildings, tunnels, and pipelines [1-3]. Resources are essential for any construction project, and available resources must be matched with the requirements of all activities within a project for balance in resource allocation. The objective of resource leveling is to achieve the most efficient resource consumption without increasing the prescribed make span of the project, which means minimizing variations and the peaks and valleys in resource usage that occur during project execution $[4,5]$.

Methods that calculate resource leveling fall broadly into three categories: analytical methods, heuristic methods, and metaheuristic methods [6-8]. Geng et al. [6] introduced a directional ant colony optimization algorithm to solve nonlinear resource leveling problems. The algorithm can efficiently improve the convergence rate and the quality of solutions for real project scheduling. Rieck et al. [7] presented new mixed-integer linear model formulations and domainreducing preprocessing techniques. The authors proposed a cutting plan to strengthen the models and to reduce peaks and valleys for resource requirements at particular points. Kyriklidis et al. [8] proposed an effective resolution of resource leveling optimization problems by using nature inspired intelligent methodologies.

Since the 1950s, many lectures on network-based methods have proposed resource leveling. For example, Younis and Saad [9] proposed a model to deal with multiple resource leveling, and the model formulation is interfaced by the CPM scheduling results. Neumann and Zimmermann [10] presented polynomial heuristic procedures for different types of resource leveling problems for projects with minimum and maximum time lags between project activities. Ponz-Tienda et al. [11] presented an adaptive genetic algorithm to level resources in networks. The authors provided a flexible and powerful decision support system that enables practitioners to choose between different feasible solutions to a problem in realistic environments. However, CPM was found to be ineffective for projects with repetitive characteristics where the same basic unit is repeated several times [12].

Many studies have attempted to find an optimum solution for resource leveling in repetitive project scheduling. Georgy [13] presented a genetic algorithm for resource leveling using a linear scheduling method (LSM). The author's algorithm 


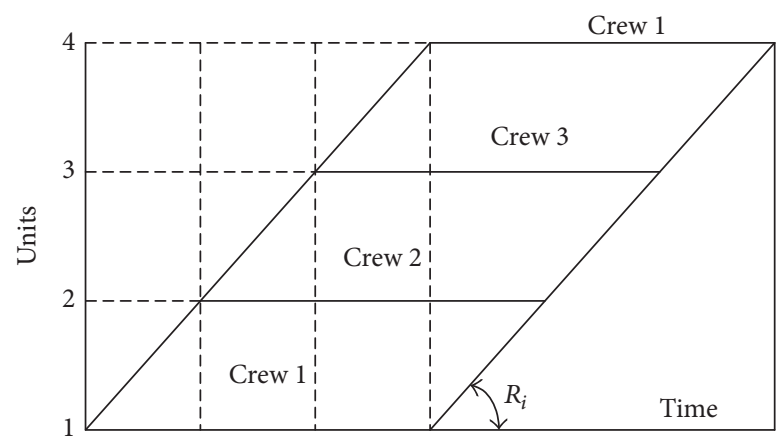

FIGURE 1: The relation of crews and rate.

adopted function optimizers to overcome the primary shortcoming of mathematical solutions for the resource leveling problem, but it required more resource usage and added variables. Elwany et al. [14] represented a linear programming model for single resource allocation and smoothening in repetitive construction projects. Lucko [15] built on an analysis of the criticality of linear schedules with unique singularity functions. The author proposed equation models such as the first moment area to minimize the objective function toward a level profile, but the model is complex for exchanging objective function.

Line of balance (LOB) is widely used in repetitive projects. LOB performs resource allocation but ignores resource leveling. Damci et al. [16] developed a genetic algorithmbased resource leveling model in LOB schedules. The authors observed that the proposed resource leveling model provided a smoother resource utilization histogram while maintaining optimum productivity and meeting project duration. The proposed model in this current study is of benefit to contractors because it provides a resource leveling procedure for a repetitive project without any productivity loss.

This paper develops a resource leveling algorithm in LOB. For this purpose, it introduces a kind of special activity defined as the backward controlling activity by Zhang and Qi [17]. The variation in the duration of the backward controlling activity changes the project duration in an opposite direction. The proposed algorithm in this paper is designed to level resources by reducing the number of crews participating on the backward controlling activities. The algorithm is tested by an illustrative pipeline project.

\section{Line of Balance Scheduling}

LOB is a method for managing the information concerning how many crews should be employed in each activity and how to arrange these crews in units and assumes that a unit should be completed by one crew. To set up an LOB schedule visually, Figure 1 shows an LOB representation in which a horizontal line represents time, a vertical line represents a unit, and each sloping bar represents one activity. The slope of each bar represents the planned rate of each activity.

$$
R_{i}=\frac{n-1}{T_{L}-T_{l}} .
$$

The productivity of the activity can be related to the number of crews and expressed as follows:

$$
R_{i}=\frac{C_{i}}{D_{i}} .
$$

$R_{i}$ represents the productivity of the activity $i, T_{L}$ is the target deadline of activity $i, T_{l}$ is the duration of the last activity in first unit, and $n$ is the number of units. $C_{i}$ is the number of crews arranged in activity $i$, and $D_{i}$ is the duration of the activity $i$ in a unit.

According to (2) the number of crews can be obtained from $C_{i}=R_{i} \times D_{i}$.

This paper considers the finish-to-start relationship between activities, which means an activity in each unit can only start after the completion of its predecessor activities in the same unit. Accordingly, the start and finish times of activity $i$ in each unit should be delayed by an additional period $\Delta_{i}$. Start time $S_{i j}$ and finish time $F_{i j}$ of activity $i$ in unit $j$ can be shown as follows:

$$
\begin{aligned}
& S_{i j}=\frac{1}{R_{i}}(j-1)+\Delta_{i}, \\
& F_{i j}=S_{i j}+D_{i}, \\
& \Delta_{i}=\max _{\substack{r \in P_{i} \\
j=1,2, \ldots, J}}\left(F_{r j}-S_{i j}\right),
\end{aligned}
$$

where $P_{i}$ is the set of its predecessor activities.

This paper assumes that the principles of "optimum crew size" and "nature rhythm" are also applied [18]. "Optimum crew size" is a principle that implies that productivity will suffer if the crew size is different than the optimum crew size. The principle of "natural rhythm" allows shifting of the start times of an activity forward or backward for different units of production by changing the number of crews employed. An increase in the number of working teams would increase productivity. In Figure 2(a), the productivity of the activity is one unit per day when only one crew is utilized. If two crews are employed, the productivity becomes two units per day. Figure 2(c) shows that if the production rate of the activity fails to achieve two units per day, this leads to an increase in worker hours per unit because of the idle time of crews.

To calculate the daily resource usage for an activity, the scheduler must know the duration of the activity for a unit, the productivity, and the number of crews active in a day. In practical engineering, productivity is difficult to determine; however, required worker hours for an activity in a unit, the number of workers per crew, and the number of working hours per day are easily obtained. Therefore, the duration of an activity $i$ in a unit is calculated by the following magnitude:

$$
\begin{aligned}
D_{i} & =\frac{\mathrm{Rh}_{i}}{w_{i} \times h}, \\
\operatorname{Re}_{i t} & =C_{i t} \times w_{i},
\end{aligned}
$$

where $\mathrm{Rh}_{i}$ represents required worker hours of activity $i$ in a unit by the optimum crew size, $w_{i}$ is the number of workers 


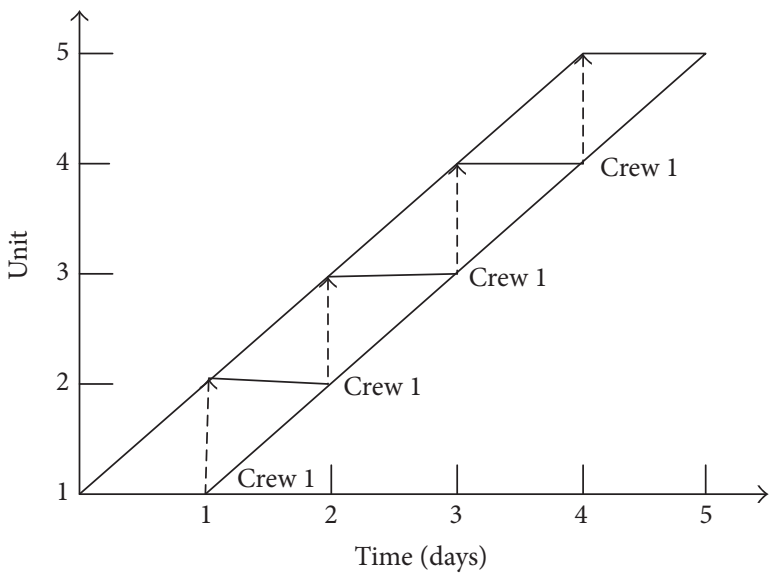

(a)

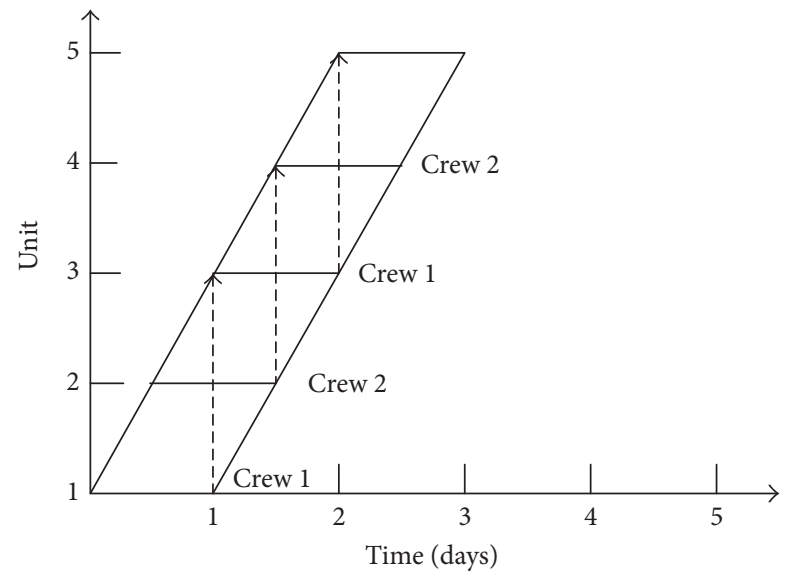

(b)

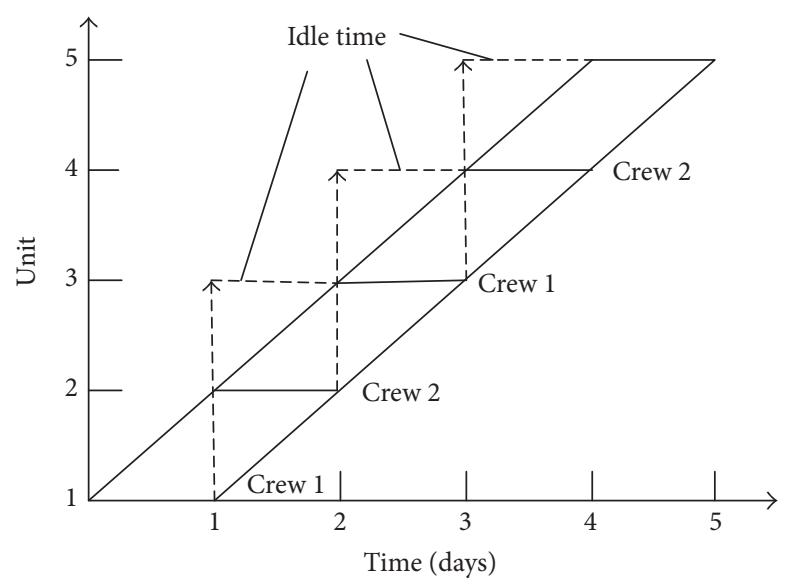

(c)

FIgURE 2: LOB scheduling with different productivity.

per crew for activity $i, h$ is the number of working hours per day. $\mathrm{Re}_{i t}$ is the resource usage required for activity $i$ in day $t$, and $C_{i t}$ is the number of crews active in day $t$.

\section{Backward Controlling Activity in LOB}

Researchers have already found an unexpected phenomenon that the extension of the duration of some activities would shorten the project duration $[19,20]$. In network models, this type of activity is defined as the backward critical activity by Elmaghraby and Kamburowski [21]. Zhang and Qi [17] proposed a method for identifying three different types of controlling activities in LSM, that is, the forward controlling activity, the backward controlling activity, and the point controlling activity. The forward controlling activity is the controlling activity we usually refer to. If it is delayed, the project will be delayed. The point controlling activity is the activity that only its start time or finish time change will affect the project duration. The backward controlling activity is special. If its duration is prolonged, the project duration could be reduced. The essential feature of the backward controlling activity is that it has a higher production rate than its preceding and succeeding controlling activity.
These three types of controlling activities exist in LOB too. On the controlling path, if the production rate of an activity is speedier than its preceding and succeeding activity, it is identified as the backward controlling activity. If the duration of the backward controlling activity is prolonged, it means that the production rate is reduced, and then its first unit can be started earlier without violating the constraint from the preceding controlling activity. Thus, the succeeding activity could start earlier, and the project could be finished earlier.

For example, there is a project including activities A, B, and $\mathrm{C}$, and all of them are in the controlling path, as shown in Figure 3. The productivity of activity B is $4 / 3$ units per day, which is greater than the productivity of activities A and $C$ at $1 / 2$ units per day. Therefore, activity $A$ and $C$ are forward controlling activities, and activity B is a backward controlling activity. The project duration could be reduced if we accelerate activity $\mathrm{A}$ and $\mathrm{C}$ by allocating more crews on them, which is the most common way to shorten the project duration. But there is another way to achieve the goal by reducing crews on the backward controlling activity, that is, activity B. After two crews on activity B are fired, the succeeding controlling activity $\mathrm{C}$ can be started $t$ days earlier, and the project can be finished $t$ days earlier, as shown 


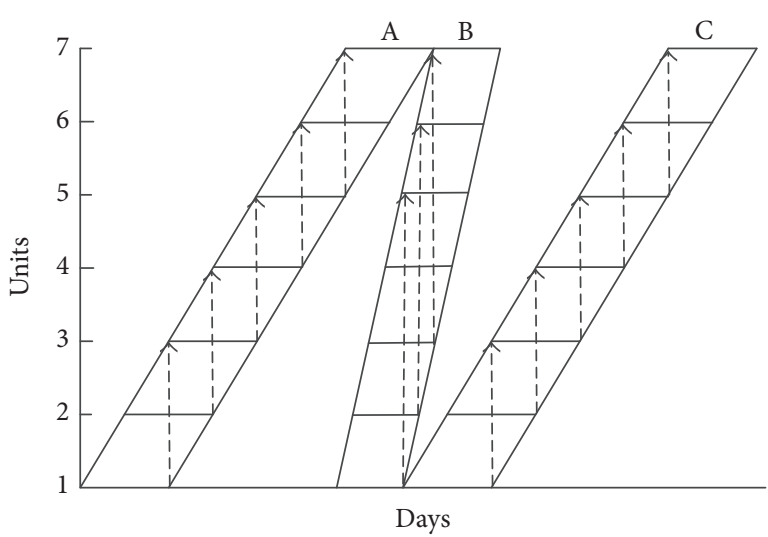

(a)

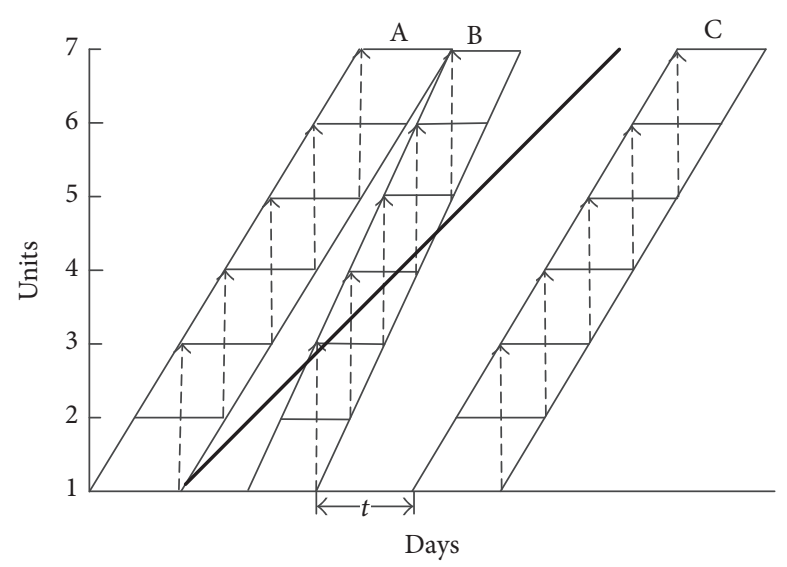

(b)

FIgURE 3: The backward controlling activity in LOB.

in Figure 3(b). In a certain range, reducing the productivity of a backward controlling activity can shorten the project duration.

However, a backward controlling activity does not always shorten the project duration after reducing crews. If activity $i$ is a backward controlling activity, a minimum slope exists. After adjustment, the productivity of activity $i$ cannot slow more than the minimum slope, which can be expressed as follows:

$$
\mathrm{MR}=\frac{n-1}{S_{u, n}-D_{i}-F_{p, 1}},
$$

where MR is the minimum rate, $n$ is the number of units, $p$ and $u$ are the preceding controlling activity and the succeeding controlling activity of activity $i, D_{i}$ is the duration of the activity $i$ in a unit, $S_{u, n}$ is the start time of the activity $u$ in the last unit, and $F_{p, 1}$ is the finish time of the activity $p$ in the first unit.

In Figure 3(b), the slope of the thick black line represents the minimum production rate. The productivity of activity $\mathrm{B}$ cannot be slower than the minimum production rate, or the project duration will be prolonged.

\section{Algorithm for Resource Leveling}

The backward controlling activity brings two advantages to resource leveling. On the one hand the crews are reduced on the backward controlling activity, which means possible leveler resource usage; on the other hand the project duration could be shortened, which means the project will not be delayed. The proposed algorithm in this paper aims to achieve resource leveling by reducing crews on the backward controlling activities and shifting its start times. Figure 4 shows the flowchart of the algorithm.

The productivity of all crews that consist of an optimum number of workers will be up to the maximum because more or fewer workers than the optimum crew size would result in lower productivity. To ensure productivity change linearly, all units in any activity are always executed by the optimum crew size. The following principles are followed to level the resource of a whole project.

(1) Only the backward controlling activities are candidates for adjustment, for instance, activity B in Figure 3. The productivity of these activities should be greater than the preceding controlling activities and succeeding controlling activities.

(2) If the number of crews in the backward activity is greater than one and the production of the activity is not slower than the minimum rate after reducing one crew, then one crew of the backward controlling activity could be fired, and the number of crews should be updated. If any of these two conditions is not met, the identified backward controlling activity cannot be adjusted. When all of the backward controlling activities are adjusted, the sum of absolute values of the deviations between resource usage on any day and the average resource usage should be calculated.

(3) When a cycle is finished, the deviation values of postresource leveling and preresource leveling should be compared, and the smaller value should be noted. Step 2 should not be repeated until the terminal situation is met.

(4) There are two terminal situations. First, the backward controlling activities no longer exist. Second, the backward controlling activities do exist but only one crew is employed. Either situation would disrupt the computing stop.

Various objective functions are presented in previous studies for resource leveling. Resource leveling is to minimize resource fluctuations within the deadline. Demeulemeester and Herroelen [22] defined "resource leveling aims at completing the project within its deadline with a resource usage which is as level as possible over the entire project horizon." The resource leveling problem can be formulated conceptually as follows: 


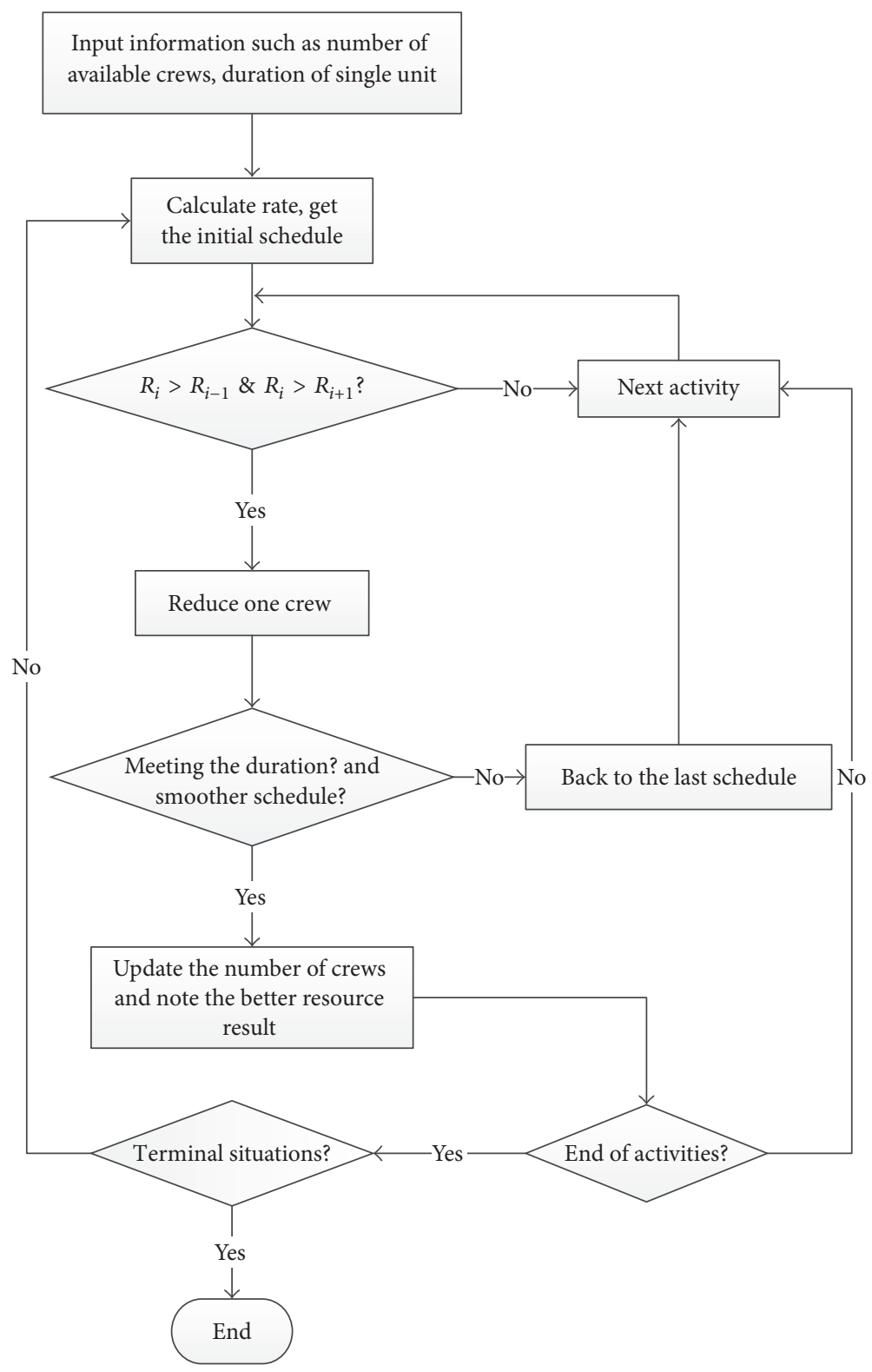

Figure 4: Flowchart of the algorithm.

$$
\begin{array}{ll}
\text { Minimize } & \sum_{m=1}^{m} \sum_{t=1}^{\delta_{n}} c_{k}\left(u_{k t}\right) \\
\text { subject to } & f_{i} \leq f_{j}-d_{j} \\
& f_{n} \leq \delta_{n},
\end{array}
$$

where $\delta_{n}$ is the project deadline, $f_{i}$ is the finish time of activity $i(0<i \leq n)$, and $u_{k t}$ is the availability of the resource $k$ in the period $t$.

Damci and Polat [23] investigated the effects of different objective functions on resource utilization histograms in CPMs. They studied nine different resource leveling objective functions generating different resource utilization histograms. To prove the proposed model's effect, this current study uses the same objective function as Damci et al. [16].
The objective function minimizes the sum of the absolute deviations between daily resource requirements and the average resource requirement. This is one of the most commonly used objective functions for resource leveling in linear scheduling methods [14]. The formulation can be expressed as

$$
z=\min \sum_{t=1}^{T} \mid \mathrm{PR}_{t}-\text { Ave } \mid,
$$

where $t$ is the day under consideration, $T$ is the project duration, $\mathrm{PR}_{t}$ is the resource usage required on day $t$, and Ave is the average resource usage requirement for the duration of the project.

To maintain job continuity for the same repetitive activity, the typical scheduling precedence relationship between the 
TABLE 1: The Information for the pipeline project.

\begin{tabular}{|c|c|c|c|c|c|c|}
\hline Activity & $\begin{array}{l}\text { Required worker } \\
\text { hours to finish unit }\end{array}$ & $\begin{array}{l}\text { Number of } \\
\text { workers }\end{array}$ & $\begin{array}{l}\text { Daily working } \\
\text { hours }\end{array}$ & Duration (days) & Number of crews & $\begin{array}{c}\text { Productivity } \\
\text { rate }\end{array}$ \\
\hline $\begin{array}{l}\text { (A) Locating and } \\
\text { clearing }\end{array}$ & 96 & 6 & 8 & 2 & 2 & 1 \\
\hline (B) Excavating & 64 & 8 & 8 & 1 & 2 & 2 \\
\hline (C) Laying aggregate & 80 & 10 & 8 & 1 & 3 & 3 \\
\hline (D) Laying pipes & 84 & 7 & 8 & 1.5 & 2 & 1.33 \\
\hline (E) Testing & 80 & 10 & 8 & 1 & 4 & 4 \\
\hline (F) Backfilling & 96 & 6 & 8 & 2 & 5 & 2.5 \\
\hline (G) Compacting & 144 & 9 & 8 & 2 & 2 & 1 \\
\hline
\end{tabular}

controlling activities can be finish-to-start. This implies that a successor activity can start only once its predecessor has finished. The formulation can be shown as the following equation:

$$
\begin{aligned}
S_{i j} & >F_{p j}, \\
F_{M N} & <T,
\end{aligned}
$$

where $p$ represents all predecessors of the activity $i$ and $F_{M N}$ represents finish time of the last activity in the last unit.

\section{Example}

A pipeline project presented by Damci et al. [16] is used to test the proposed resource leveling model. The pipeline is $26 \mathrm{~km}$ in length and expected to be completed in 65 days and consists of seven consecutive activities: (1) locating and clearing (activity A), (2) excavating (activity B), (3) laying aggregate (activity C), (4) laying pipes (activity D), (5) testing (activity E), (6) backfilling (activity F), and (7) compacting (activity G). The initial schedule was accelerated using the principles of Tokdemir et al. [24], that is, by increasing the number of crews in selected activities to complete the project in 65 days without resource limitations. Table 1 shows the project information. Although other resources are necessary to complete this pipeline project's activities, only workers were considered in this study for demonstration purposes.

Figure 5(a) shows the initial scheduling, and Figure 5(b) shows the scheduling given by Damci et al. [16]. They obtained a better result than the initial schedule by adjusting the number of crews in some units of activity B and activity F. Figure 5(c) shows the scheduling given by this study. The LOB chart obtained by the proposed algorithm in this study is totally different from the former schedule. The project can be completed in 48 days after resource leveling. The number of employed crews is 2, 1, 1, 1, 1, 2, 2 arranged on activities from locating and clearing (activity A) to compacting (activity G). All activities have an equal productivity of one unit per day, except activity D, which is executed in 0.67 units per day.

The total workforce used in the project is composed of the sum of the workers used in each activity through the entire project (2,093 workers). The total absolute value of deviations from the average is 1,390 , and the maximum number of workers is 102 in the initial schedules, as shown in Figure 6(a).
The average resource usage of 33 is calculated by dividing the total resources (2,093 workers) used by the whole project duration of 65 days.

Damci et al. [16] achieved a better result, although they only adjusted two activities. The authors have the same total resource usage and project duration as the initial schedule. The total absolute value of the deviations between resource usage on any day and the average resource usage is 1,037 [16], which represents an improvement in resource leveling of $25 \%$ compared to the initial schedule, as shown in Figure 6(b). And the maximum resource usage is reduced from 102 to 89.

This study designed a MATLAB program to execute the design algorithm. The major benefit of this tool is highspeed computing and user-friendly language. The use of a MATLAB program to solve this problem requires the input of the initial number of crews and productivity. In this case, after performing a set of adjustments based on backward controlling activities, the proposed model achieves better leveling and reduced project duration. The duration of the project is 48 days after resource leveling, and the average resource usage is 43.6 workers, as shown in Figure 6(c). Because the worker value cannot be noninteger, the result is rounded up to 44 . The sum of the absolute deviations between daily resource usage and average resource usage is 591, which shows a leveling of $57.5 \%$ compared with the initial schedule, and which shows a leveling of $43 \%$ compared with Damci et al.s [16]. The maximum resource usage is reduced from Damci et al.'s result 89 to 77 .

The proposed resource leveling algorithm follows the principal of adjusting the backward controlling activity. Once the number of crews is reduced in a backward controlling activity, its preceding controlling activity or succeeding controlling activity may become the backward controlling activity. Because the backward activity is represented by the activities that have a higher productivity than the preceding and succeeding controlling activity, the productivity of all activities would tend to achieve resource leveling after a set of adjustments because of a reduction in crews. The advantages of the proposed model in this study are as follows. First, effective resource leveling is obtained while the project duration can meet or even beat the deadline. Second, the algorithm process limits the complex principles required to adjust the LOB schedule, which simplifies practical operations. 


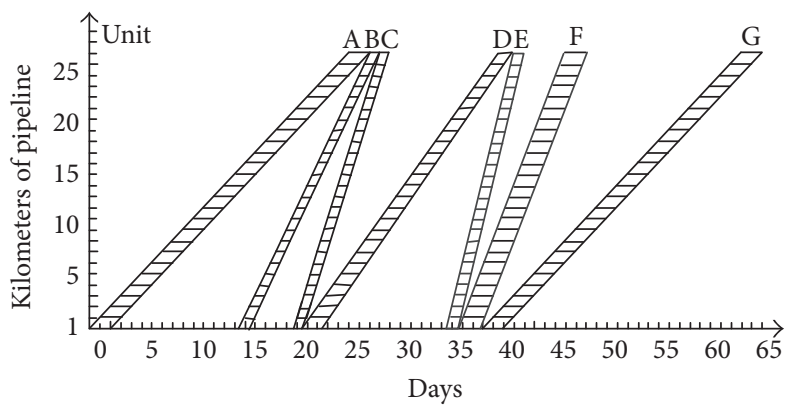

(a) The initial LOB schedule

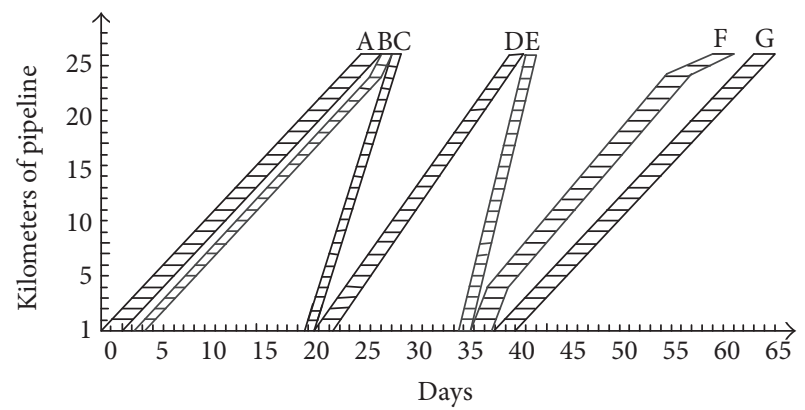

(b) LOB scheduling in Damci et al's study

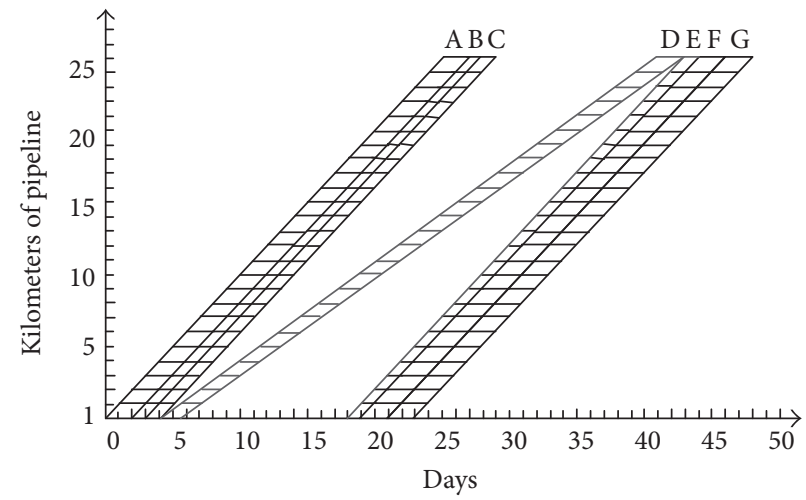

(c) LOB scheduling in this study

Figure 5: The LOB chart with different scheduling.

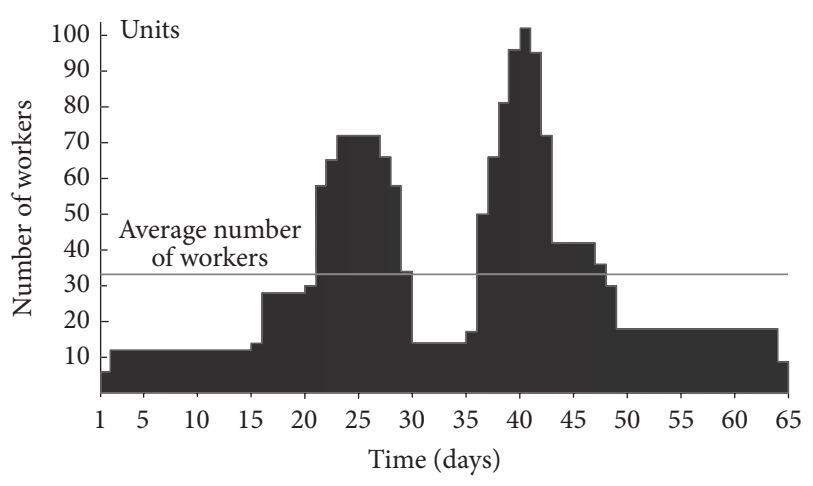

(a) The resource histogram by the initial schedule

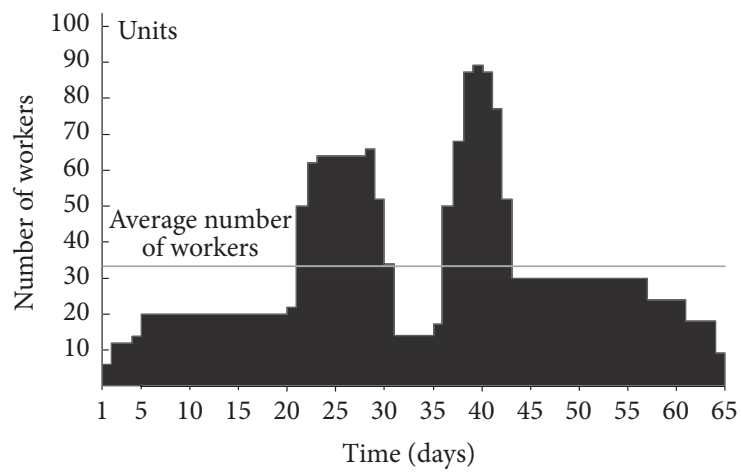

(b) The resource histogram of schedules in Damci et al.'s study

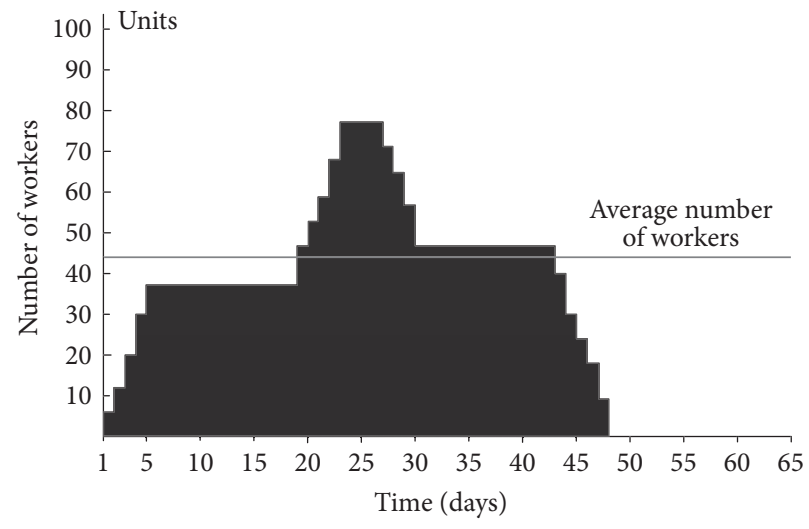

(c) The resource histogram of schedules in this paper

FiguRE 6: The resource histogram of different schedules. 
Of course, the proposed method has limitations: the effect of resource leveling depends on whether there are backward controlling activities in LOB and whether it can be adjusted.

\section{Conclusion}

An appropriate scheduling method is crucial for successful construction project completion. LOB is one of the most suitable methods for resource management in repetitive projects, but resource leveling has not been adequately considered in the LOB schedule. This paper developed a resource leveling algorithm based on backward controlling activity in LOB. The presented algorithm for resource leveling achieved a better result by reducing the number of crews in the backward controlling activity enabling a shift in start and finish times. Moreover, the project can be finished ahead of the deadline.

It should be noted that the proposed method works only when the backward controlling activities exist and when they can be adjusted, because the method only considers adjusting the backward controlling activities. And the overall quality of resource leveling depends on the backward controlling activities in the initial scheduling. But in repetitive projects the backward controlling activity exists commonly, because the productivities of all activities are usually different. It is very rare that the productivities of all activities are equal, or become bigger and bigger or smaller and smaller. Meanwhile, only a single resource and an application project with 7 activities are discussed in this paper. Further study will consider developing the method for multiple resources leveling problems and large-scale repetitive projects.

\section{Competing Interests}

The authors declare that they have no competing interests.

\section{Acknowledgments}

The authors would like to acknowledge the Natural Science Foundation of China (Contract no. 71271081) and the Fundamental Research Funds for the Central Universities (13ZD08).

\section{References}

[1] D. B. Ashley, "Simulation of repetitive-unit construction," American Society of Civil Engineers, Journal of the Construction Division, vol. 106, no. 2, pp. 185-194, 1980.

[2] S. M. Amini and G. Heravi, "Schedule compression for construction projects by interruption in LOB scheduling," AACE International Transactions, vol. 4, pp. 1-18, 2009.

[3] D. Arditi, P. Sikangwan, and O. B. Tokdemir, "Scheduling system for high rise building construction," Construction Management and Economics, vol. 20, no. 4, pp. 353-364, 2002.

[4] K. Neumann, C. Schwindt, and J. Zimmermann, Project scheduling with time windows and scarce resources, Springer, Berlin, Germany, Second edition, 2003.

[5] R. B. Harris, Precedence and Arrow Networking Techniques for Construction, John Wiley \& Sons, New York, NY, USA, 1978.
[6] J.-Q. Geng, L.-P. Weng, and S.-H. Liu, "An improved ant colony optimization algorithm for nonlinear resource-leveling problems," Computers and Mathematics with Applications, vol. 61, no. 8, pp. 2300-2305, 2011.

[7] J. Rieck, J. Zimmermann, and T. Gather, "Mixed-integer linear programming for resource leveling problems," European Journal of Operational Research, vol. 221, no. 1, pp. 27-37, 2012.

[8] C. Kyriklidis, V. Vassiliadis, K. Kirytopoulos, and G. Dounias, "Hybrid nature-inspired intelligence for the resource leveling problem," Operational Research, vol. 14, no. 3, pp. 387-407, 2014.

[9] M. A. Younis and B. Saad, "Optimal resource leveling of multiresource projects," Computers and Industrial Engineering, vol. 31, no. 1-2, pp. 1-4, 1996.

[10] K. Neumann and J. Zimmermann, "Resource levelling for projects with schedule-dependent time windows," European Journal of Operational Research, vol. 117, no. 3, pp. 591-605, 1999.

[11] J. L. Ponz-Tienda, V. Yepes, E. Pellicer, and J. Moreno-Flores, "The Resource Leveling Problem with multiple resources using an adaptive genetic algorithm," Automation in Construction, vol. 29, no. 1, pp. 161-172, 2013.

[12] I.-T. Yang and C.-Y. Chang, "Stochastic resource-constrained scheduling for repetitive construction projects with uncertain supply of resources and funding," International Journal of Project Management, vol. 23, no. 7, pp. 546-553, 2005.

[13] M. E. Georgy, "Evolutionary resource scheduler for linear projects," Automation in Construction, vol. 17, no. 5, pp. 573-583, 2008.

[14] M. H. Elwany, I. E. Korish, M. A. Barakat, and S. M. Hafez, "Resource smoothening in repetitive projects," Computers and Industrial Engineering, vol. 35, no. 3-4, pp. 415-418, 1998.

[15] G. Lucko, "Integrating efficient resource optimization and linear schedule analysis with singularity functions," Journal of Construction Engineering and Management, vol. 137, no. 1, pp. 45-55, 2011.

[16] A. Damci, D. Arditi, and G. Polat, "Resource leveling in line-ofbalance scheduling," Computer-Aided Civil and Infrastructure Engineering, vol. 28, no. 9, pp. 679-692, 2013.

[17] L. H. Zhang and J. X. Qi, "Controlling path and controlling segment analysis in repetitive scheduling method," Journal of Construction Engineering and Management, vol. 138, no. 11, pp. 1341-1345, 2012.

[18] D. Arditi, O. B. Tokdemir, and K. Suh, "Challenges in line-ofbalance scheduling," Journal of Construction Engineering and Management, vol. 128, no. 6, pp. 545-556, 2002.

[19] K. G. Mattila and D. M. Abraham, "Linear scheduling: past research efforts and future directions," Engineering Construction and Architectural Management, vol. 5, no. 3, pp. 294-303, 1998.

[20] R. B. Harris and P. G. Ioannou, "Scheduling projects with repeating activities," Journal of Construction Engineering and Management, vol. 124, no. 4, pp. 269-278, 1998.

[21] S. E. Elmaghraby and J. Kamburowski, "The analysis of activity networks under generalized precedence relations (GPRs)," Management Science, vol. 38, no. 9, pp. 1245-1263, 1992.

[22] E. L. Demeulemeester and W. S. Herroelen, Project SchedulingA Research Handbook, Department of Applied Economics Katholieke Universiteit, Leuven, Belgium, 2002.

[23] A. Damci and G. Polat, "Impacts of different objective functions on resource leveling in construction projects: a case study," Journal of Civil Engineering and Management, vol. 20, no. 4, pp. 537-547, 2014. 
[24] O. B. Tokdemir, D. Arditi, and C. Balcik, "ALISS: advanced linear scheduling system," Construction Management and Economics, vol. 24, no. 12, pp. 1253-1267, 2006. 


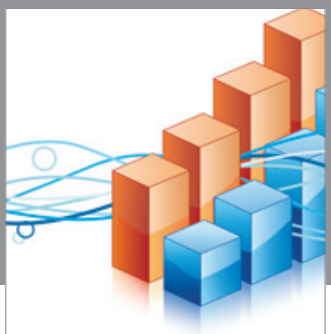

Advances in

Operations Research

vatem alat4

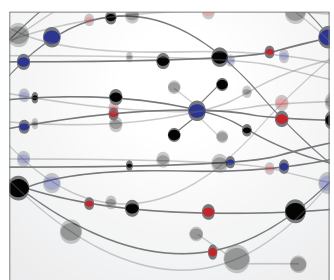

\section{The Scientific} World Journal
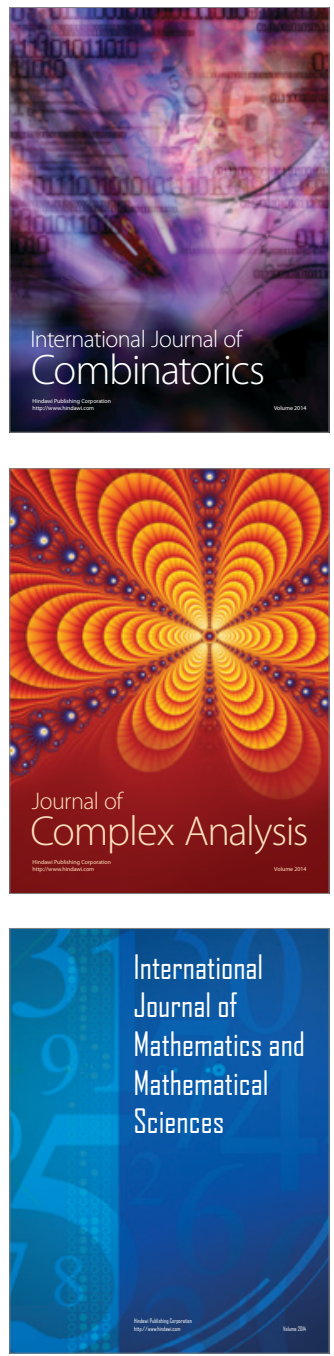
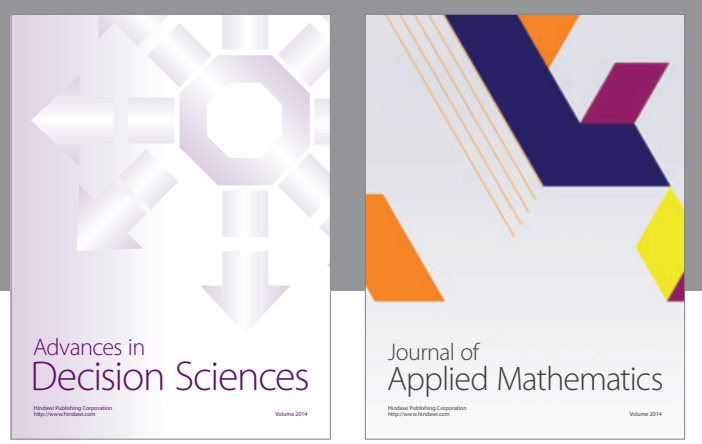

Algebra

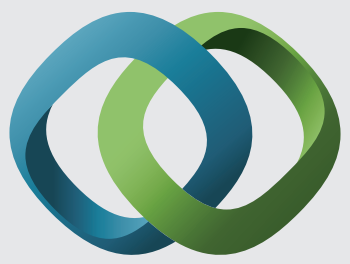

\section{Hindawi}

Submit your manuscripts at

https://www.hindawi.com
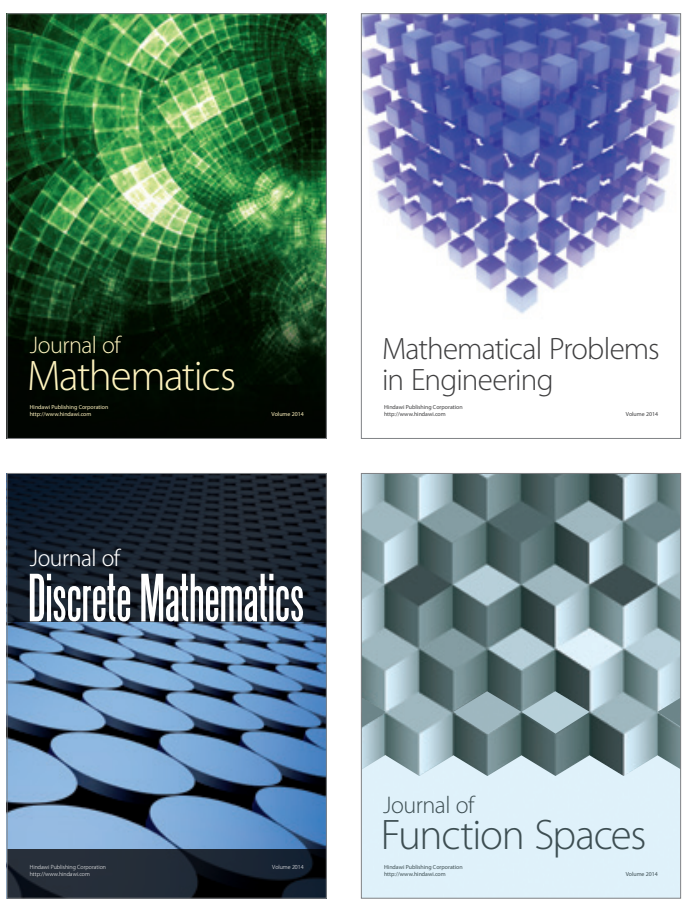

Mathematical Problems in Engineering
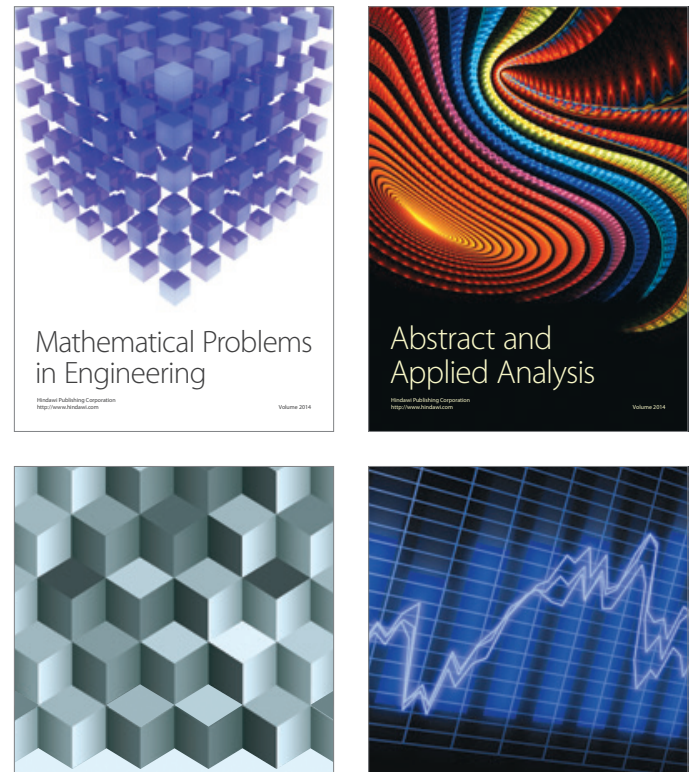

Journal of

Function Spaces

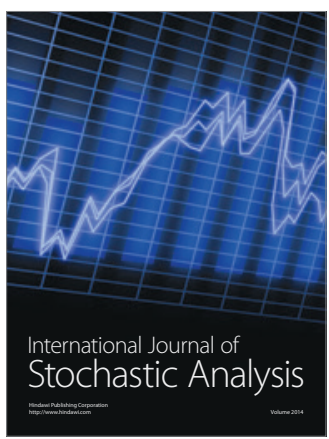

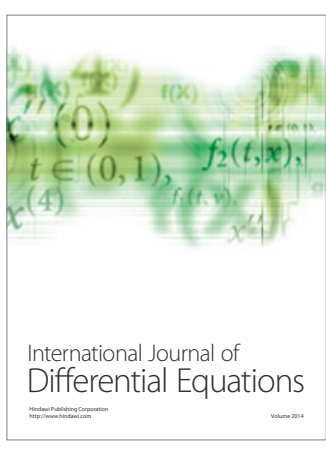
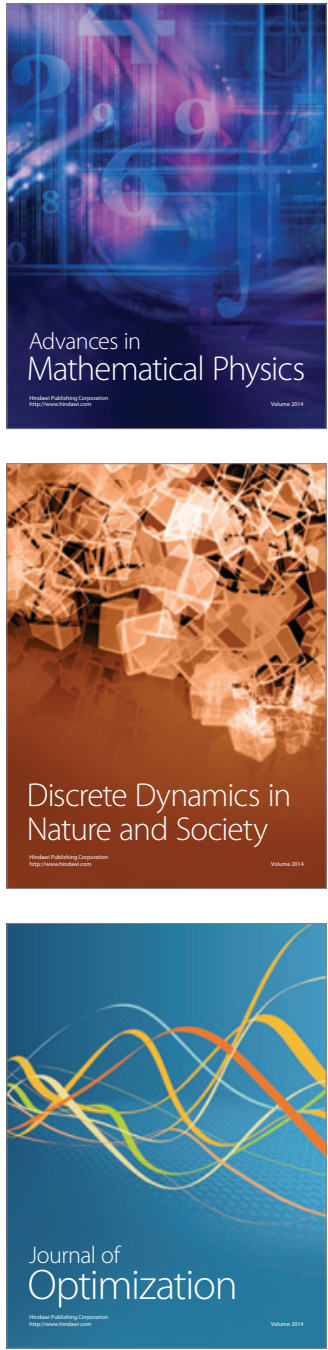